\title{
As polêmicas faces do Ensino Médio
}

\author{
Camila Ferreira Lopes Paiva \\ Universidade Estadual Paulista "Júlio de Mesquita Filho", Rio Claro, SP - Brasil. \\ mila_ferreira_lopes@hotmail.com \\ Joyce Mary Adam de Paula e Silva \\ Universidade Estadual Paulista "Júlio de Mesquita Filho", Rio Claro, SP - Brasil. \\ joyce@rc.unesp.br
}

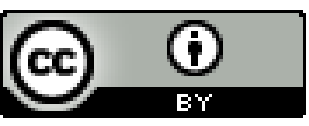

Educação: teoria e prática, Rio Claro, SP, Brasil - eISSN: 1981-8106

Está licenciada sob Licença Creative Common

\section{Resumo}

Este artigo discute os problemas enfrentados pelo Ensino Médio, como a dicotomia entre trabalho e formação propedêutica, juntamente com a evasão escolar, que é ainda alarmante. Para contribuir com a discussão, foram utilizadas as concepções de Gramsci (1985) sobre a escola unitária, que oferece a formação propedêutica a todos os cidadãos para a função de dirigente. A superação da dicotomia e da evasão escolar, especificamente no Ensino Médio, ao contrário do que muitos pensam, implica na substituição dessa sociedade meritocrática e individualista, na qual o sujeito é totalmente responsabilizado pelo seu sucesso e pelo seu fracasso, por uma sociedade, na qual todos os bens materiais e culturais estejam disponíveis a todos os cidadãos. Logo, a solução não está em medidas remediáveis, como o governo tem proposto, pois os problemas têm raízes mais profundas do que imaginamos. Diante disso, constatamos que a escola sozinha não fará a mudança revolucionária na sociedade, no entanto, a revolução não se fará sem a escola. Não há como superar essa sociedade alienada com ações persistentemente alienadas.

Palavras-chave: Ensino Médio. Educação Profissional. Evasão escolar.

\section{The polemic sides of the Senior High School}

\section{Abstract}

This article discusses the problems faced by high school, as the dichotomy between work and training workup and truancy, the teaching at this level is still alarming. To contribute to the discussion, we used the ideas of Gramsci (1985) about the unitary school that offers training which prepared for all citizens to a manager. Overcoming the dichotomy and 
truancy specifically in high school, opposing to what many people think, implies the replacement of that individualistic and meritocratic society, in which the person himself is totally responsible for his success and his failure, where all goods and cultural materials are available to all citizens. Therefore, the solution lies not in remediable actions, as the government has proposed that the problems have deeper roots than we think. Thus, we think that the school itself will not make a revolutionary change in society; however, the revolution will not happen without school. There is no way to overcome this alienated society with persistently alienated actions.

Keywords: High School. Vocational Education. Truancy.

\section{Introdução}

Quando pensamos em Ensino Médio no Brasil, logo nos deparamos com a ideia de dualidade estrutural, a qual se configura em dois caminhos bastante criticados por Gramsci (1985): um que prepara o jovem para exercer a função de dirigente; e o outro, que o prepara para o mundo do trabalho em cursos específicos de formação profissional na rede pública ou privada. Especialistas consideram essa dicotomia na constituição do Ensino Médio como a raiz dos males desse nível de ensino, e defendem que a confiança na solução desse problema apenas pela definição das finalidades, conteúdos e metodologia, torna seu enfrentamento muito simplista.

O problema se torna bem mais complexo se pensarmos que a concepção, a permanência e a natureza unilateral da formação oferecida pelo Ensino Médio são definidas pelas relações de poder típicas de uma sociedade dividida em classes sociais.

Devido à sua relevância escolar e social, considera-se que o Ensino Médio brasileiro merece estudos em perspectiva sócio-histórica, que procurem compreender os privilégios que as elites tiveram nesse campo escolar, assim como as exclusões de grupos sociais desfavorecidos. Esses estudos podem colocar o foco sobre os saberes e as habilidades que são prescritos e colocados em prática no Ensino Médio/Secundário. Também, podem contemplar as clientelas dos estabelecimentos de Ensino Médio/Secundário, levando em consideração marcadores sociais como gênero, etnia, religião e frações de classes sociais. A produção de reflexões acadêmicas sobre o Ensino Médio é uma forma de contribuir para a sua transformação.

Segundo Kuenzer (2000), a iniciativa estadual criou, primeiro, as escolas profissionais, no início do século XX; somente nos anos 40, criou o Ensino Médio, e, desde então, essas 
redes sempre estiveram de alguma forma articuladas. Mais precisamente, a formação profissional no Brasil passou a ser responsabilidade do Estado, em 1909, com a criação de dezenove escolas de artes e ofícios nas diferentes unidades da federação. Essas escolas pretendiam obedecer à finalidade moralizadora da formação do caráter pelo trabalho, retirando os órfãos e os pobres da rua, visto que a demanda por um desenvolvimento industrial, à época, era praticamente inexistente (Kuenzer, 2000). A autora relata que até 1932, junto ao curso primário, havia a possibilidade de realização do curso rural e profissional com quatro anos de duração, que poderia se suceder pela formação exclusiva para o mundo do trabalho no ginásio, com o normal, técnico comercial e técnico agrícola.

A educação escolar das elites tinha início no ensino primário, passava pelo ensino secundário propedêutico e terminava no ensino superior, dividido em ramos profissionais, por meio de exames, apenas para os que concluíssem pelo menos a 5 a série do ginásio. Havia, portanto, uma predeterminação do caminho educacional a ser seguido pelos indivíduos que iriam desempenhar as funções intelectuais e as instrumentais, numa sociedade dividida entre capital e trabalho, entre atividades de planejamento e de execução, que utilizava como base o taylorismo-fordismo. Essa pedagogia baseada no trabalho taylorista-fordista prioriza os modos de fazer, o disciplinamento do trabalhador, e não considera necessário a este ter acesso ao conhecimento científico, e menos ainda que o trabalhador domine intelectualmente as práticas socioprodutivas para a construção da sua autonomia.

Kuenzer (2000) afirma que a partir dos anos 40, com a diferenciação e o desenvolvimento de vários ramos profissionais nos setores secundário e terciário, as escolas e os cursos profissionalizantes começaram a se multiplicar, incluindo o Serviço Nacional de Aprendizagem Industrial (SENAI) e o Serviço Nacional de Aprendizagem Comercial (SENAC), com a reforma Capanema em 1942. A partir dessa reforma, foram criados também os cursos médios de 2 o ciclo, científico e clássico, com três anos de duração e com o objetivo de preparar o jovem para o ensino superior. A reforma Capanema também contribuiu para a formação profissional voltada para o instrumental em nível médio de 20 ciclo, como o agrotécnico, o comercial técnico, o industrial técnico e o normal, sem acesso ao ensino superior. 
A criação do SENAI e SENAC complementou a dicotomia no sistema de ensino, pois combinou a iniciativa pública e a privada para atender ao crescente desenvolvimento industrial que passou a exigir mão de obra qualificada. Como tentativa de articular a modalidade científica e a profissional, foi permitido, aos alunos de cursos profissionalizantes, prestar exames de adaptação para ter acesso aos processos de seleção para o ensino superior.

Com a promulgação da Lei de Diretrizes e Bases da Educação Nacional (Lei ㄲo 4.024/1961), há o reconhecimento, pela primeira vez, da integração completa do ensino profissional ao sistema regular de ensino, equivalendo os cursos profissionalizantes e os propedêuticos, para a possibilidade de prosseguimento dos estudos.

Também, os cursos do SENAI e SENAC passaram a ser equivalentes ao ensino fundamental e médio. De acordo com Kuenzer (2000), a Lei no 5.692/1971 tentou substituir a dualidade no Ensino Médio, estabelecendo a profissionalização compulsória nesse nível de ensino e deixando, assim, que todos cursassem a mesma trajetória. No entanto, embora tenham sido criadas diversas medidas para superar a dualidade estrutural no Ensino Médio, infelizmente ela ainda persiste nesse nível de ensino.

Em 1982, a Lei no 7.044 trouxe o retorno das escolas propedêuticas para as elites e das profissionalizantes para os trabalhadores, mantendo a equivalência. Essas tentativas fracassadas de superação da dualidade estrutural no Ensino Médio só reafirmaram a ideia de que, tendo origem na estrutura de classes, essa adversidade não pode ser resolvida apenas no âmbito do projeto político pedagógico escolar, afinal o problema seria apenas remediado e não resolvido.

Partindo da premissa de que a reelaboração do Ensino Médio depende mais do âmbito político que pedagógico, o desafio torna-se ainda maior, já que é necessária a sua democratização, que não implica apenas na ampliação de vagas, afinal a massificação do ensino exige espaços físicos adequados, aumento do quadro docente e capacitação para esses professores.

Enquanto tem aumentado significativamente o acesso ao Ensino Fundamental, no Ensino Médio e nível superior o acesso ainda é muito reduzido, devido, entre outros motivos 
segregadores, à necessidade de trabalhar dos jovens desfavorecidos economicamente, que, para manter sua sobrevivência, optam pelo emprego precário, na grande maioria das vezes. O acesso a esse nível de ensino e aos cursos nobres exige tempo de dedicação, financiamento de material técnico, bibliográfico e cursos complementares à formação, que são reservados aos jovens de renda mais alta, com ressalva para algumas exceções de jovens, que mesmo egressos de famílias de baixa renda, conseguem obter uma boa formação com muito esforço e acabam servindo de confirmação à tese da meritocracia.

Gramsci (1985) enfatiza a importância da escola unitária em sua última fase, para a formação de valores fundamentais de autodisciplina intelectual e autonomia moral, que poderão ser direcionados, posteriormente, para os estudos da ciência ou para a prática produtiva, visando minimizar a forma brusca e mecânica da passagem da escola para a vida, e criar uma consciência moral e social homogênea.

Sendo assim, não podemos substituir o caráter básico do Ensino Médio, pela educação profissional independente de escolaridade. Entretanto, a formação científicotecnológica e sócio-histórica deve ser completada por conteúdos do mundo do trabalho, na parte diversificada, sem que se configurem os cursos profissionalizantes típicos do taylorismo-fordismo. Afinal, em nossa sociedade, para a maioria dos jovens, o exercício de um trabalho digno será a única possibilidade de continuar seus estudos em nível superior, o que remete ao Ensino Médio, que deve atender a essas duas demandas: o acesso ao trabalho e a continuidade dos estudos com competência e compromisso.

Segundo o artigo 35 da Lei no 9.394, de 20 de dezembro de 1996 (LDB),

\footnotetext{
O ensino médio, etapa final da educação básica, com duração mínima de três anos, terá como finalidades:

I - a consolidação e o aprofundamento dos conhecimentos adquiridos no ensino fundamental, possibilitando o prosseguimento de estudos;

II - a preparação básica para o trabalho e a cidadania do educando, para continuar aprendendo, de modo a ser capaz de se adaptar com flexibilidade a novas condições de ocupação ou aperfeiçoamento posteriores;

III - o aprimoramento do educando como pessoa humana, incluindo a formação ética e o desenvolvimento da autonomia intelectual e do pensamento crítico; IV - a compreensão dos fundamentos científico-tecnológicos dos processos produtivos, relacionando a teoria com a prática, no ensino de cada disciplina (BRASIL, 1996, p. 11).
} 
Fazendo uma leitura ingênua da lei, temos que as finalidades e os objetivos do Ensino Médio se resumem no compromisso de educar o jovem para participar política e produtivamente do mundo das relações sociais concretas, com comportamento ético e compromisso político, através do desenvolvimento da autonomia intelectual e da autonomia moral. Mas, se fizermos uma leitura crítica da lei, é possível nos perguntarmos: será que as escolas oferecem toda essa formação aos jovens? Ou, melhor dizendo: será que esta é a intenção do sistema escolar atual?

Para o Ensino Médio público atingir essas finalidades é necessário que se elabore uma síntese entre o geral e o particular aos jovens que necessitam do trabalho para a sobrevivência e/ou prosseguimento dos estudos. Como dizia Gramsci (1985), as escolas de Ensino Médio, secundárias e profissionais, são antidemocráticas pela sua finalidade, e não pelo conteúdo ensinado, já que preparam os indivíduos de acordo com a posição social que assumirão na sociedade.

Por lidar com indivíduos cultural e economicamente heterogêneos, o Ensino Médio deve contemplar a diversidade, como previsto na LDB:

\begin{abstract}
Art. 26. Os currículos do ensino fundamental e médio devem ter uma base nacional comum, a ser complementada, em cada sistema de ensino e estabelecimento escolar, por uma parte diversificada, exigida pelas características regionais e locais da sociedade, da cultura, da economia e da clientela.

§ 5 o Na parte diversificada do currículo será incluído, obrigatoriamente, a partir da quinta série ${ }^{1}$, o ensino de pelo menos uma língua estrangeira moderna, cuja escolha ficará a cargo da comunidade escolar, dentro das possibilidades da instituição (BRASIL, 1996, p. 8).
\end{abstract}

No artigo 11 das Diretrizes Curriculares Nacionais para o Ensino Médio (BRASIL, 1998b) também se prevê:
Na base nacional comum e na parte diversificada será observado que:
II - a parte diversificada deverá ser organicamente integrada com a base nacional comum, por contextualização e por complementação, diversificação, enriquecimento, desdobramento, entre outras formas de integração;
III - a base nacional comum deverá compreender, pelo menos, 75\% (setenta e cinco por cento) do tempo mínimo de 2.400 (duas mil e quatrocentas) horas, estabelecido pela lei como carga horária para o ensino médio;
IV - além da carga mínima de 2.400 horas, as escolas terão, em suas propostas pedagógicas, liberdade de organização curricular, independentemente de distinção entre base nacional comum e parte diversificada;

\footnotetext{
${ }^{1}$ A partir de 2009, denominado sexto ano, de acordo com a Resolução SE- 98/2008.
} 
V - a língua estrangeira moderna, tanto a obrigatória quanto as optativas, serão incluídas no cômputo da carga horária da parte diversificada (BRASIL, 1998b, p. 6).

Em 2009, o Ministério da Educação (MEC) apresentou ao Conselho Nacional de Educação (CNE) a proposta, já aprovada, de aumentar a carga horária mínima do Ensino Médio de 2.400 para 3.000 horas, sendo 1.000 horas anuais. Segundo Ramos (2009), a mudança ainda não aconteceu em todo o Brasil, mas o Estado de São Paulo já aderiu às 1.000 horas anuais, com a permanência de 200 dias letivos; o devido aumento da carga horária para estudos estritamente profissionalizantes e a distribuição de $75 \%$ para dedicação à base nacional comum; e $25 \%$ para a parte diversificada. A preparação básica para o trabalho deverá ser contemplada pela base nacional comum e pela parte diversificada.

A parte diversificada, segundo as DCNEM (BRASIL, 1998b), deve estar integrada à base nacional comum, trabalhando as articulações entre teoria e prática, conhecimento geral e específico, cultura e trabalho, porém não pode ser entendida como fragmentação ou dualidade, mas, sim, como superação dessa característica que, ao longo da historia, vem condicionando a finalidade do Ensino Médio.

Essa superação não pode acontecer sem uma autonomia do Sistema Estadual, compreendendo que as Diretrizes são linhas que fornecem orientação sobre a direção a ser seguida, e não permitem o uso de práticas autoritárias ou mecanismos de controle prévio por parte de qualquer instância do sistema público ou da direção da escola. Também não podem praticar atitudes discriminatórias, por meio do reforço de privilégios ou exclusões.

No exercício de sua autonomia, cabe às escolas elaborar seus projetos de avaliação, de forma articulada ao Sistema Estadual de Educação, com a intenção de facilitar a visualização dos resultados mais gerais e específicos. Contudo, para auxiliar o planejamento em nível estadual e escolar, o Sistema Estadual e as escolas devem analisar os resultados dos processos desenvolvidos pelo MEC, para compreender, explicar os dados obtidos e eliminar possíveis distorções. Na verdade, não é bem o que acontece, pois nos sistemas de avaliação criados para o Ensino Médio, fica clara a visão individualizada com que é tratado o processo educacional, quando atribui ao aluno, principalmente no Exame Nacional do Ensino Médio 
$(E N E M)^{2}$, a responsabilidade individual pelo sucesso ou fracasso demonstrados pelo exame. Segundo Sousa e Zákia (2003), o ENEM mede um resultado pontual, que é interpretado de forma individualizada, e desconsidera as condições do sistema de ensino que, sem dúvida, são corresponsáveis pela produção de competências ou incompetências dos alunos. Sem contar ainda os sistemas estaduais de avaliação, que responsabilizam as escolas pelos resultados, por meio de uma bonificação àquelas que tiverem sucesso nos exames, homogeneizando a metodologia dos docentes que trabalham numa mesma escola, e a capacidade de aprendizagem dos alunos.

Tão importante quanto a elaboração de um sistema sensato de avaliação é a organização de diretrizes, para que sejam compatíveis com a finalidade do Ensino Médio. Dessa maneira, a Resolução no 1, de 3 de fevereiro de 2005, atualiza as Diretrizes Curriculares Nacionais para o Ensino Médio e para a Educação Profissional Técnica de Nível Médio às disposições do Decreto no 5.154/2004, alterando o artigo 12 da Resolução CNE/Câmara de Educação Básica (CEB) 3/98, com a seguinte redação:

§ 30 A articulação entre a Educação Profissional Técnica de nível médio e o Ensino Médio se dará das seguintes formas:

I. integrada, no mesmo estabelecimento de ensino, contando com matrícula única para cada aluno;

II. concomitante, no mesmo estabelecimento de ensino ou em instituições de ensino distintas, aproveitando as oportunidades educacionais disponíveis, ou mediante convênio de intercomplementaridade;

III. subsequente, oferecida somente a quem já tenha concluído o Ensino Médio (BRASIL, 2005, p. 1).

Vale lembrar que não se pode organizar o curso integrado com duas partes distintas, concentrando em uma delas a formação do Ensino Médio; e, em outra, a formação técnica, com um ano ou mais; pois seria, na realidade, a forma concomitante ou subsequente travestida de integrada. Esse processo, além de contrariar a legislação atualizada, mostra um retrocesso pedagógico quando reforça a indesejada dicotomia entre conhecimentos e entre teoria e prática.

\footnotetext{
${ }^{2}$ Exame utilizado atualmente como processo seletivo pelas universidades públicas e pelo programa ProUni e como certificação de conclusão do Ensino Médio.
} 
Dessa maneira, para obter o diploma de Técnico de Nível Médio, o aluno deve concluir os seus estudos de Educação Profissional Técnica de Nível Médio e do Ensino Médio, paralelamente, na forma integrada. Para obter seu certificado de conclusão do Ensino Médio, o aluno deve concluir, simultaneamente, a habilitação Técnica de Nível Médio. Os diplomas de cursos de educação profissional Técnica de Nível Médio, quando registrados, têm validade nacional e habilitam ao prosseguimento de estudos na educação superior, como previsto na LDB (1996).

A mesma Resolução altera, também, a nomenclatura dos cursos e programas de Educação Profissional, nos seguintes termos:

Art. 3o A nomenclatura dos cursos e programas de Educação Profissional passará a ser atualizada nos seguintes termos:

I. “Educação Profissional de nível básico" passa a denominar-se "formação inicial e continuada de trabalhadores";

II. "Educação Profissional de nível técnico" passa a denominar-se "Educação Profissional Técnica de nível médio";

III. "Educação Profissional de nível tecnológico" passa a denominar-se "Educação Profissional Tecnológica, de graduação e de pós-graduação” (Brasil, 2005, p. 1).

E, igualmente, modifica a carga horária dos cursos e programas de Educação Profissional, da seguinte forma:

Art. 5o Os cursos de Educação Profissional Técnica de nível médio realizados de forma integrada com o Ensino Médio, terão suas cargas horárias totais ampliadas para um mínimo de 3.000 horas para as habilitações profissionais que exigem mínimo de 800 horas; de 3.100 horas para aquelas que exigem mínimo de 1.000 horas e 3.200 horas para aquelas que exigem mínimo de 1.200 horas.

Art. 60 Os cursos de Educação Profissional Técnica de nível médio realizados nas formas concomitante ou subsequente ao Ensino Médio deverão considerar a carga horária total do Ensino Médio, nas modalidades regular ou de Educação de Jovens e Adultos e praticar a carga horária mínima exigida pela respectiva habilitação profissional, da ordem de 800, 1.000 ou 1.200 horas, segundo a correspondente área profissional (BRASIL, 2005, p. 2).

Segundo Nascimento (2011), o CNE aprovou a mudança na organização curricular do Ensino Médio para quatro eixos de formação: trabalho, ciência, tecnologia e cultura. Essas aparentes mudanças, não trazem inovações tão significativas assim, afinal as DCNEM já 
contemplavam essa organização por áreas do conhecimento da base nacional comum, condensadas em três áreas: Linguagens, Códigos e suas Tecnologias; Ciências da Natureza, Matemática e suas Tecnologias e Ciências Humanas e suas Tecnologias, tratadas com interdisciplinaridade e contextualização, inclusive para Educação Física e Arte, como componentes curriculares obrigatórios. A Educação Física prevê a possibilidade de dispensa prevista pela LDB (1996) apenas para alunos que cumpram jornada de trabalho igual ou superior a seis horas; tenham mais de trinta anos de idade; estiverem prestando serviço militar inicial e/ou que tenham prole.

O termo tecnologia aparece em todas as áreas do conhecimento para expressar a contextualização das áreas e disciplinas com o mundo do trabalho. Dessa maneira, a presença da tecnologia no Ensino Médio remete diretamente às atividades relacionadas à aplicação dos conhecimentos e habilidades constituídos ao longo da educação básica, dando expressão concreta à preparação básica para o trabalho, prevista na LDB 1996 e na Resolução CNE/CEB n.o 04/99, que institui as Diretrizes Curriculares Nacionais para a Educação Profissional de Nível Técnico.

\footnotetext{
Art. 60 Entende-se por competência profissional a capacidade de mobilizar, articular e colocar em ação valores, conhecimentos e habilidades necessários para o desempenho eficiente e eficaz de atividades requeridas pela natureza do trabalho.

Parágrafo único. As competências requeridas pela educação profissional, considerada a natureza do trabalho, são as:

I - competências básicas, constituídas no ensino fundamental e médio;

II - competências profissionais gerais, comuns aos técnicos de cada área;

III - competências profissionais específicas de cada qualificação ou habilitação (BRASIL, 1999, p. 2).
}

Como se observa, os textos legislativos estão imbuídos de concepções neoliberais, nas quais a palavra de ordem é competência, a qual pauta-se no indivíduo apartado o máximo possível do conhecimento para afastá-lo da possibilidade de conquistar a parte que Ihe pertence da riqueza produzida por ele mesmo. Essa constatação nos provoca certa desconfiança quanto à formulação das leis, afinal qual será a real intenção dos legisladores para com a formação do cidadão, se cada vez mais percebemos indivíduos competentes e menos descobridores do conhecimento crítico e contra-ideológico? 
Duarte (2001) nos lembra que a organização curricular do Ensino Médio por competências baseia-se no princípio do aprender a aprender, que coloca a educação em função de atender às exigências do processo de valorização do capital. Dessa maneira, segundo o autor, a educação destina-se a formar indivíduos criativos, não para revolucionar radicalmente a realidade social, mas, sim, para encontrar novas formas de ação que permitam o melhor enquadramento ao sistema de reprodução do capital.

\section{A evasão no Ensino Médio}

Além da dualidade estrutural, o Ensino Médio no Brasil é assombrado, desde muito tempo, pela evasão escolar. Segundo estudos feitos por Sousa (2011), a evasão escolar entre jovens é preocupante, já que dos 3,6 milhões de jovens que se matriculam no Ensino Médio, apenas 1,8 milhão concluem-no. Contudo, a taxa de evasão no Ensino Médio é de 13,3\%, enquanto que nas séries finais do Ensino Fundamental é de 6,7\%. Conforme a autora, o Ensino Médio possui cerca de 8 milhões de alunos, dos quais 50\% não concluem seus estudos.

Segundo Ferrari (1975, apud SOUSA, 2011, p.2), vários fatores podem contribuir para a evasão escolar, dentre eles:

Escola: não atrativa, autoritária, professores despreparados, insuficiente, ausência de motivação, etc.

Aluno: desinteressado, indisciplinado, com problema de saúde, gravidez, etc.

Pais/responsáveis: não cumprimento do pátrio poder, desinteresse em relação ao destino dos filhos, etc.

Social: trabalho com incompatibilidade de horário para os estudos, agressão entre os alunos, violência em relação a gangues, etc.

A evasão escolar pode ser o resultado da somatória desses fatores e, não necessariamente, de um específico. Não podemos isentar a responsabilidade das políticas de governo, que oferecem um Ensino Médio ainda confuso quanto à sua finalidade, com condições, muitas vezes, precárias em relação ao conteúdo, à formação de valores e ao preparo para o mundo do trabalho.

Outro elemento que contribui para a evasão escolar é a repetência dos alunos não apenas no Ensino Médio, mas também no Ensino Fundamental, o que ocasiona a distorção 
idade-série, pois muitos jovens chegam ao Ensino Médio fora da faixa etária adequada e, por isso, abandonam a escola.

Quando se trata de ensino noturno, a evasão torna-se mais preocupante ainda, porque o ensino ocorre com a mesma metodologia das turmas do diurno e, em alguns casos, com a mesma carga horária, porém, sem o rigor utilizado nessas turmas. O que provoca incertezas nos jovens quanto à qualidade e utilidade do ensino para a vida prática, levandoos a desistir dos estudos.

Diante de todos esses obstáculos, que culminam no abandono à escola, muitos jovens optam por cursar a Educação de Jovens e Adultos (EJA), no Ensino Médio, que tem a duração em média de um ano e meio. Podem, ainda, realizar o Exame Nacional para Certificação de Competências de Jovens e Adultos (Encceja), que tem como objetivo avaliar as habilidades e competências básicas de jovens e adultos que não tiveram oportunidade de acesso à escolaridade regular na idade apropriada. O participante, que deve ter no mínimo 18 anos, se submete a uma prova e, se conseguir o mínimo de pontos exigido, obtém a certificação de conclusão do Ensino Médio. Segundo o MEC, em 2008 o Encceja contou com cerca de 780 mil inscritos, sendo 60\% para o Ensino Médio e $40 \%$ para o Ensino Fundamental. O jovem tem, ainda, desde 2009, a possibilidade de utilizar o ENEM como certificação de conclusão do Ensino Médio, substituindo o Encceja.

Além dessas opções, os jovens e adultos têm a possibilidade de cursar o Ensino Médio a distância, segundo o Decreto no 57.011, de 23 de maio de 2011, do estado de São Paulo:

Artigo 10 - Fica criada, no âmbito da Secretaria da Educação, a Escola Virtual de Programas Educacionais do Estado de São Paulo - EVESP, subordinada e sob supervisão pedagógica da Coordenadoria de Estudos e Normas Pedagógicas.

Artigo 2ㅇ - A Escola Virtual de Programas Educacionais do Estado de São Paulo EVESP destina-se a oferecer programas educacionais regulares, especiais e de capacitação em situações que requeiram atendimento a necessidades de grupos específicos da população.

Artigo 30 - Os cursos e programas oferecidos pela EVESP serão ministrados dentro da dinâmica da rede estadual de ensino, por meio de metodologias baseadas no uso intensivo das tecnologias de informação e de comunicação (SÃO PAULO, 2011, p. 1). 
O referido decreto diz que o governo do Estado de São Paulo direcionará o programa de educação virtual a grupos específicos da população, visando oferecer, aos jovens e adultos, oportunidades educacionais apropriadas, consideradas as suas características, seus interesses, suas condições de vida e trabalho. No entanto, como finalização da Educação Básica, o caráter presencial do Ensino Médio é um direito que todos devem contemplar, embora possa ser organizado de diferentes formas, como consta na lei.

Na verdade, o que é cada vez mais inadmissível é o fato de existirem excluídos da educação presencial, seja por isolamento geográfico, por baixa renda ou por condições precárias de vida e trabalho. E, mais preocupante ainda, é perceber que as medidas remediáveis são cada vez mais bem aceitas.

Diante de cursos de duração mais curta e da flexibilidade dos cursos virtuais, o aluno que encontra dificuldades em permanecer no Ensino Médio regular vê uma possibilidade de retornar aos estudos quando tiver necessidade e/ou interesse.

Alguns estudos utilizam duas abordagens diferentes para explicar as possíveis causas da evasão escolar, uma delas refere-se a fatores externos à escola; e outra, a fatores internos à escola. A primeira delas, segundo Meksenas (1992), indica que alunos de nível socioeconômico mais baixo têm um menor índice de rendimento escolar, porque precisam trabalhar para seu sustento e da família e, por isso, chegam à escola já cansados e desmotivados. Essa realidade é diferente daquela dos alunos favorecidos economicamente, os quais possuem tempo para estudar e se dedicar às atividades complementares, de aperfeiçoamento e de lazer.

Os defensores da segunda abordagem, como Bourdieu-Passeron (1975), consideram a escola como responsável pelo sucesso ou fracasso dos alunos e, principalmente, pelo fracasso daqueles pertencentes à classe pobre da população, atribuindo um caráter reprodutor à escola.

Para esses autores que consideram a escola como reprodutora das desigualdades sociais, o discurso presente no âmbito educacional, que responsabiliza o aluno pelo seu fracasso escolar, legitima o pensamento neoliberal e os argumentos da sociedade 
meritocrática, a qual considera como promissor e esforçado o indivíduo bem sucedido, e como fracassado aquele que não se preparou para enfrentar a competitividade.

Segundo Sousa (2011), os maiores problemas enfrentados na atualidade, no Ensino Médio, são turmas lotadas, conteúdos extensos e específicos, e professores despreparados para lidar com a complexidade da sala de aula. Diante disso, a autora destaca que,

1. Ao fim do 3을 ano, apenas $25 \%$ dos alunos demonstram domínio do conteúdo de Língua Portuguesa e 10\% de Matemática;

2. Entre os 10 milhões que têm entre 15 e 17 anos, só a metade está no Ensino Médio. A outra metade, 1,8 milhão de alunos, desistiu de estudar e 3,5 milhões continuam presos pelos obstáculos do Ensino Fundamental;

3. O 1ํano do Ensino Médio é o que apresenta o maior número de desistências (...) (SOUSA, 2011, p. 28).

Para amenizar a situação alarmante de evasão no Ensino Médio, a Emenda Constitucional no 59, de 2009, altera os incisos I e VII do art. 208, da Constituição Federal, tornando esse nível de ensino obrigatório assim como o Ensino Fundamental, visando facilitar o acesso e a permanência na escola. Tal mudança deverá ser implementada progressivamente até 2016, com o apoio técnico e financeiro da União.

Entretanto, se por um lado não podemos negar que o Brasil é um país com sérias desigualdades, onde muitas famílias vivem em condições de miséria, que impulsionam o jovem a buscar meios de subsistência em detrimento do prosseguimento dos estudos; por outro lado, não podemos reduzir a questão da evasão escolar apenas ao aspecto econômico. Afinal, a evasão escolar pode ser uma legitimação à ideologia neoliberal, quando esta minimiza a importância e a necessidade dos estudos para alguns e prioriza para outros. Assim, o aluno excluído social e economicamente sente desmotivação perante um sistema educacional que não o prepara adequadamente para ingressar na universidade e, consequentemente, para exercer uma digna profissão.

Essa legitimação acontece de forma natural, assim como o destino ao qual tantos jovens acreditam que não podem fugir. Assim como na Segunda Guerra Mundial era natural para os nazistas enviar judeus para as câmaras de gás, hoje é também concebível e justificável que jovens não inclusos à classe dominante abandonem a escola. Como um 
destino que, segundo Alaminos (2005), justifica o descumprimento tácito de leis e a negação de direitos aos considerados desafortunados.

Nesse contexto, como a escola se organiza para readaptar o jovem evadido ao meio escolar, de forma que ele consiga prosseguir e concluir seus estudos? Se os objetivos para a escola média já foram delineados, o problema está na efetivação desses objetivos ou no entendimento sobre eles?

De acordo com Ferrari (1975, apud SOUSA, 2011), o principal agente do processo para o combate à evasão escolar é o professor, já que mantém um contato diário com o aluno, pode identificar sua ausência frequente sem justificativa, e iniciar o processo de resgate, comunicando o caso à direção escolar. Volpi (2009) acrescenta que é necessária a aproximação do professor com seus alunos, para contribuir com a permanência do jovem na escola; no entanto, não podemos nos esquecer que, numa sala com cinquenta alunos, fica humanamente impossível ter uma relação mais próxima com cada um deles.

Por isso, é importante lembrar que a raiz do problema está muito mais profunda do que imaginamos, afinal, oferecer o Bolsa Família, as bonificações e premiações às escolas, aos professores e aos alunos, não erradica o problema, apenas o maquia.

\section{Considerações finais}

A sobrevivência num mundo estrangulado pela crise do trabalho assalariado e pela ênfase no indivíduo como responsável pelas suas (in)competências, tem provocado a falta de utopia nos jovens, levando-os ao individualismo, ao hedonismo e à violência, em face da perda de significado da vida individual e coletiva.

Sendo o Ensino Médio uma etapa da educação básica, que atende essa faixa etária da população, e por estar imbuído em tantas controvérsias, esse nível de ensino merece uma atenção especial de pesquisadores, para se entender melhor o seu funcionamento e, a partir desse entendimento, buscar caminhos para a superação desses problemas, não apenas no aspecto pedagógico, mas principalmente no âmbito político.

É importante compreender que a efetiva democratização da educação de qualidade e com formação unitária só será possível com a reorganização da sociedade em outro modo de produção, onde todos os bens materiais e culturais estejam disponíveis a todos os 
cidadãos. Enquanto essa reorganização não acontece, precisamos da escola para contribuir com a superação da sociedade alienada, por meio de uma formação consciente e contraideológica. Afinal, a escola sozinha não fará a mudança revolucionária na sociedade, mas essa revolução não se fará sem a escola.

\section{Referências:}

ALAMINOS, C. Evasão escolar na adolescência: necessidade ou ideologia?. In: SIMPÓSIO INTERNACIONAL DO ADOLESCENTE, 1., 2005, São Paulo. Proceedings... São Paulo: Faculdade de Educação da Universidade de São Paulo, 2005.Não paginado. Disponível em: $<$ http://www.proceedings.scielo.br/scielo.php?pid=MSC0000000082005000200001\&script= sci_arttext>. Acesso em: 03 jun. 2011.

BOURDIEU, P; PASSERON, J. C. A reprodução: elementos para uma teoria do sistema de ensino. Rio de Janeiro: Francisco Alves, 1975.

BRASIL. Casa Civil. Lei 7.044, de 18 de outubro de 1982. Altera dispositivos da Lei no 5.692, de 11-8-1971, referentes à profissionalização do ensino de 20 Grau (Lei revogada pelo artigo 92 da Lei no 9.394 de 20-12-1996). Disponível em: <http://www.planalto.gov.br/ccivil_03/leis/L7044.htm>. Acesso em: 12 jun. 2011.

BRASIL. Casa Civil. Lei 9394, de 20 de dezembro de 1996. Estabelece as Diretrizes e Bases da Educação Nacional. Disponível em: <http://www.planalto.gov.br/ccivil_03/leis/l9394.htm>. Acesso em: 06 jun. 2011.

BRASIL. Ministério da Educação. Conselho Nacional de Educação. Parecer no 15, de 1 de junho de 1998a . Discute as Diretrizes Curriculares Nacionais para o Ensino Médio. Disponível em: <http://portal.mec.gov.br/cne/arquivos/pdf/1998/pceb015_98.pdf>. Acesso em: 10 jun. 2011.

BRASIL. Ministério da Educação. Conselho Nacional de Educação. Resolução no 3, de 26 de junho de 1998b. Institui as Diretrizes Curriculares Nacionais para o Ensino Médio. Disponível em: <http://portal.mec.gov.br/cne/arquivos/pdf/rceb03_98.pdf>. Acesso em: 12 jun. 2011.

BRASIL. Ministério da Educação. Resolução n. 4, de 8 de dezembro de 1999. Institui as Diretrizes Curriculares Nacionais para a Educação Profissional de Nível Técnico. Disponível em: <http://portal.mec.gov.br/dmdocuments/rceb004_99.pdf>. Acesso em: 6 jun. 2011. 
BRASIL, Decreto n 5.154: Regulamenta o § 2으 do art. 36 e os arts. 39 a 41 da Lei no 9.394, de 20 de dezembro de 1996, que estabelece as diretrizes e bases da educação nacional, e dá outras providências. Diário Oficial da União [da República Federativa do Brasil], Brasília, DF, n. 142, 26 jul. de 2004. Seção 1. p. 18. Disponível em: <http://www.jusbrasil.com.br/diarios/667744/dou-secao-1-26-07-2004-pg-18/pdfView>.

Acesso em: 15 mar. 2012.

BRASIL. Ministério da Educação. Secretaria de Ensino Técnico - MEC/SETEC. Resolução no 1, de 3 de fevereiro de 2005. Atualiza as Diretrizes Curriculares Nacionais definidas pelo Conselho Nacional de Educação para o Ensino Médio e para a Educação Profissional Técnica de nível médio. Disponível em: <http://portal.mec.gov.br/setec/arquivos/pdf_legislacao/rede/legisla_rede_resol1.pdf >. Acesso em: 10 jun. 2011.

BRASIL. Casa Civil. Emenda Constitucional no 59, de 11 de novembro de 2009. Dá nova redação aos incisos I e VII do art. 208, de forma a prever a obrigatoriedade do ensino de quatro a dezessete anos. Disponível em: $<$ http://www.planalto.gov.br/ccivil_03/constituicao/emendas/emc/emc59.htm>. Acesso em: 16 jun. 2011.

BRASIL, Ministério da Educação. Encceja. Disponível em: $<$ http://portal.mec.gov.br/index.php?option=com_content\&view=article\&id=12485\&Itemid =784>. Acesso em: 12 jun. 2011.

DUARTE, N. Vigotski e o "aprender a aprender": crítica às apropriações neoliberais e pósmodernas da teoria vigotskitiana. 2.ed. Campinas: Autores Associados, 2001.

GRAMSCl, A. Os intelectuais e a organização da cultura.5.ed. Rio de Janeiro: Civilização Brasileira, 1985.

KUENZER, A. (Org.), Ensino Médio: construindo uma proposta para os que vivem do trabalho. In: Primeira Parte. São Paulo: Cortez, 2000, p. 25-93.

MEKSENAS, P. Sociologia da Educação: uma introdução ao estudo da escola no processo de transformação social. 2. ed. São Paulo: Cortez, 1992.

NASCIMENTO, C. Aluno poderá escolher área a seguir já no ensino médio: proposta do Conselho Nacional de Educação permite que cada escola dê prioridade a uma área de 
formação. A gazeta [Jornal]. 2011. Disponível em: <http://gazetaonline.globo.com/_conteudo/2011/05/noticias/a_gazeta/dia_a_dia/843520aluno-podera-escolher-area-a-seguir-ja-no-ensino-medio.html>. Acesso em: 6 jun. 2011.

RAMOS, M. Aprovadas mudanças no Ensino Médio: escolas do país podem escolher se devem aderir propostas. Diário Catarinense, Santa Catarina, n. 8484, 2009. Não paginado. Disponível em: <http://www.clicrbs.com.br/diariocatarinense/jsp/default2.jsp?uf=2\&local=18\&source=a25 65101.xml\&template=3898.dwt\&edition=12634\&section=213>. Acesso em: 6 jun. 2011.

SÃO PAULO [Estado]. Decreto no 57.011, de 23 de maio de 2011. Cria a Escola Virtual de Programas Educacionais do Estado de São Paulo - EVESP, e dá providências correlatas. Diário Oficial [Estado de São Paulo]. São Paulo, SP, n. 96, 24 mai. 2011. Seção 1, v. 121, p. 1. Disponível em: <http://www.educacao.sp.gov.br/wp-content/uploads/2011/09/DOEDecreto-n\%C2\%B0-57.011-de-23-05-2011.pdf>. Acesso em: 5 jun. 2011.

SOUSA, A. et al. Evasão escolar no ensino médio: velhos ou novos dilemas?. Vértices, Rio de Janeiro, v. 13, n. 1, p. 25-37, jan./abr. 2011. Disponível em: <http://www.essentiaeditora.iff.edu.br/index.php/vertices/article/viewFile/1220/641>.

Acesso em: 8 jun. 2011.

VOLPI, M. A escola que os jovens merecem. Revista Época, [S. I.], n. 587, não paginado, ago.2009. 